\title{
Paradiplozoon yunnanensis n. sp. (Monogenea, Diplozoidae) from Sikukia gudgeri (Cyprinidae, Barbinae) in southwest China
}

\author{
Li-xian Fan ${ }^{1,2}$, Fei-yan Meng ${ }^{1}$, Jun-ping Bai ${ }^{1}$, Wei-jiang $\mathrm{Xu}^{1,2}$, and $\mathrm{Xu}$ Wang ${ }^{1,2, *}$ \\ ${ }^{1}$ School of Life Sciences of Yunnan Normal University, Kunming, China \\ 2 Engineering Research Center of Sustainable Development and Utilization of Biomass Energy, Ministry of Education, \\ Kunming, China
}

Received 6 January 2018, Accepted 6 August 2018, Published online 7 September 2018

\begin{abstract}
Paradiplozoon yunnanensis n. sp. (Monogenea, Diplozoidae) is described from the gills of Sikukia gudgeri Smith, 1931 (Cyprinidae) collected from Jinghong Basin, a tributary of the international Lancang-Mekong River. This is the first diplozoid species from S. gudgeri and its description increases the number of Paradiplozoon species recorded in China to 25 . The new species is distinguished from congeners by a combination of morphological and molecular features. The anterior end of the median plate is thickened in the marginal area and a narrow rectangular trapeze spur connects to the anterior jaw through two separate anterior joining sclerites. The posterior end of the median plate sclerite is invaginated with a smooth strip-shaped posterior joining sclerite. Comparison of a newly obtained sequence of rRNA ITS2 with 18 other congeneric sequences from GenBank provides support for separation of the new species.
\end{abstract}

Key words: Diplozoidae, Paradiplozoon, ITS2, Sikukia gudgeri, China.

Résumé - Paradiplozoon yunnanensis n. sp. (Monogenea, Diplozoidae) de Sikukia gudgeri (Cyprinidae, Barbinae) dans le sud-ouest de la Chine. Paradiplozoon yunnanensis n. sp. (Monogenea, Diplozoidae) est décrit des branchies de Sikukia gudgeri Smith, 1931 (Cyprinidae) collecté dans le bassin de Jinghong, un affluent de la rivière internationale Lancang-Mékong. C'est la première espèce de Diplozoidae de S. gudgeri et sa description amène le nombre d'espèces de Paradiplozoon de Chine à 25. La nouvelle espèce se distingue de ses congénères par une combinaison de caractéristiques morphologiques et moléculaires. L'extrémité antérieure de la plaque médiane est épaissie dans la zone marginale et un étroit éperon trapézoïdal rectangulaire se connecte à la mâchoire antérieure par l'intermédiaire de deux sclérites antérieurs séparés. L'extrémité postérieure de la plaque sclérite médiane est invaginée avec un sclérite postérieur lisse en forme de bande. La comparaison de la séquence d'ARNr ITS2 nouvellement obtenue avec 18 autres séquences congénères de GenBank soutient la séparation de la nouvelle espèce.

\section{Introduction}

Diplozoid monogeneans (Diplozoidae Palombi, 1949) are common blood-feeding ectoparasites on the gills of cyprinid fishes. The Diplozoidae includes five genera in China [32]: Diplozoon Nordmann, 1832; Paradiplozoon Achmerov, 1974; Inustiatus Khotenovsky, 1978; Sindiplozoon Khotenovsky, 1981 and Eudiplozoon Khotenovsky, 1985. Seventy diplozoid species have been reported globally. Since the first diplozoid species was recorded from China in 1973, a total of 34 species belonging to 5 genera (24 in Paradiplozoon, 6 in Sindiplozoon, 2 in Inustiatus, 1 in Diplozoon and 1 in Eudiplozoon), have been recorded in China [32, 10, 4, 29, 30].
The lifecycle of diplozoids is direct and includes a freeswimming oncomiracidia and a post-oncomiracidial stage known as a diporpa. Two larvae (diporpa) pair and subsequently fuse permanently into the typical X-shaped body arrangement, a characteristic unique to the Diplozoidae [17]. Diplozoids have developed a sclerotized attachment apparatus for successful attachment to gills. This apparatus includes central hooks and clamps located on the haptor. The central hooks are used by the oncomiracidia, while the clamps are used by diporpa and adults to attach to the gills of the host $[16,17]$. These sclerotized structures are considered to be reliable features for species identification via morphological studies $[15,21,22]$.

\footnotetext{
*Corresponding author: wangxu@fudan.edu.cn
} 
The taxonomy of monogeneans is generally based on the morphology of sclerotized structures of their haptor [31]. In diplozoids, the sclerotized parts of the haptor, in particularly the clamps and central hook, supply the main morphological characters for species discrimination [12, 15, 19, 20, 25, 27]. The identification of species within Paradiplozoon is mainly based on the length of the central hook and the shape of certain clamp sclerites [15]. Combination of the shape of the trapeze spur and anterior joining sclerites could lead to accurate discrimination of species [22]. However, the measurements of these morphological characteristics may present high interspecific similarity [5] and show extensive variation with different hosts, water temperatures or geographical origin of parasites [21]. In Paradiplozoon homoion Bychowsky \& Nagibina, 1959, it was found that specimens parasitizing larger fish such as Rutilus rutilus have larger clamps than those from smaller fish such as Phoxinus phoxinus [21]. Furthermore, the size and shape of these sclerotized structures may easily be misinterpreted and change according to fixation and preparation [11]. The application of molecular systematics to Platyhelminthes (Cestoda, Digenea and Monogenea) has provided new insights into the interrelationship between species [23]. Due to the complicated identification of several groups of monogenean parasites, molecular markers based on speciesspecific variability have been designed and shown to be useful for identification of Monogenea. Of these molecular markers, the ITS2 region has been used to distinguish congeneric diplozoids at the species level and provided species identification similar to that made by using morphological structures [1]. Combination of morphological parameters and molecular markers is considered to be a useful approach in the study of various diplozoid taxa [3, 9, 22, 25, 28].

This study presents the identification of a new species from the gills of Sikukia gudgeri Smith, 1931 (Cyprinidae: Barbinae) combining morphological and molecular approaches. This study increases the number of species of the genus Paradiplozoon recorded in China to 25 .

\section{Materials and methods Sample collection}

In October 2012, November 2013 and May 2015, a total of 52 S. gudgeri were collected from Jinghong Basin, a main tributary of the international Lancang-Mekong River in southwest China. The taxonomic status of fish specimens was determined according to the checklist of fishes and fauna of Yunnan Province [6]. Fish were euthanized by severing the spinal cord posterior to the skull with a single cut $[6,7]$. Gills were removed and examined under an Olympus SZX7 dissecting microscope (Olympus, Japan). Specimens were washed in double-distilled water before being preserved in either $70 \%$ or $100 \%$ ethanol for morphological and molecular research, respectively.

\section{Morphological analysis}

Diplozoid specimens were stained with acetocarmine, differentiated using $\mathrm{HCl}$ in $70 \%$ ethanol, dehydrated through a graded ethanol series, cleared in clove oil or xylene and mounted in Canada Balsam. Parasites were identified according to Khotenovsky [15] and Wu et al. [32], and were examined and measured using an Olympus CX41 light microscope (Olympus, Japan) and photographed using an Olympus BX53 compound microscope equipped with differential interference contrast (DIC). A digital image analysis system (TCapture Imaging Application 4.2) was used for morphometric analysis and drawing diagnostic morphometric attachment apparatus. All sclerite parts of the attachment apparatus were named according to Jirsová et al. [13] and Al-Nasiri and Balbuena [2]. Measurements of the main characteristics of specimens are given in the results section as a mean value, with the number $(n)$ and range of measurements provided in parentheses.

\section{Molecular analysis}

Ethanol-fixed parasites were soaked for 1 day in TE buffer (pH 8.0), and genomic DNA was extracted from each individual specimen using an E.Z.N.A. ${ }^{\circledR}$ FFPE DNA Kit (OMEGA BioTek, Inc., Norcross, Georgia, USA) according to the manufacturer's instructions. According to Matějusová et al., universal eukaryotic primers, D (5'-GGCTYRYGGNGTCGATGAAGAACGCAG-3') and B1 (5'-GCCGGATCCGAATCCTGGTTAGTTTCTTTTCC $\mathrm{T}-3^{\prime}$ ), were used to amplify the ITS2 rDNA [20]. PCR amplification was performed in a $50 \mu \mathrm{L}$ volume containing $2 \mu \mathrm{L}$ of DNA template, $19 \mu \mathrm{L}$ of reaction mixture (dNTP, $10 \times$ buffer, Taq polymerase), $2 \mu \mathrm{L}$ of each primer and $25 \mu \mathrm{L}$ of double-distilled water, under the following conditions: $10 \mathrm{~min}$ at $90{ }^{\circ} \mathrm{C} ; 30$ cycles of $30 \mathrm{~s}$ at $95^{\circ} \mathrm{C}, 30$ cycles of $30 \mathrm{~s}$ at $55^{\circ} \mathrm{C}$, and $75 \mathrm{~s}$ at $72{ }^{\circ} \mathrm{C}$; and a final extension of $10 \mathrm{~min}$ at $72{ }^{\circ} \mathrm{C}$. PCR products were detected on ethidium bromide-stained $1 \%$ agarose gels. Amplicons were analysed using an ABI-3730XL Genetic Analyzer under the appropriate module (Applied by Beijing Connaught Genome Research Center Co. Ltd., Beijing). The sequences obtained were analysed using DNAMAN 7.0 and Sequencher 5.0 (Gene Codes Corp.) software before being deposited in GenBank (MF775370). The accession numbers of diplozoid species retrieved from GenBank and used in the alignment, their host species, and their sampling localities are given in Table 1. The outgroup Eudiplozoon nipponicum was used to root resultant phylogenies [25]. Base composition data, parsimony and nucleotide substitutions between pairwise distances (Kimura 2-parameter) were estimated using MEGA 6.0 and BLAST from NCBI. The robustness of topologies was assessed by 1000 bootstrap replicates.

\section{Paradiplozoon yunnanensis $\mathrm{n} . \mathrm{sp}$.}

urn:lsid:zoobank.org:act:57373A86-48E9-4336-B96B7CCF463B7862

Type host: Sikukia gudgeri Smith, 1931 (Teleostei: Cyprinidae). Fishes of the genus Sikukia can be distinguished from other fishes of barb by a short snout, large eyes, and lack of an adipose eyelid. S. gudgeri is the first species of the genus Sikukia to not have barbels and is found only in Thailand and China. 
Table 1. List of diplozoid species used for genetic comparison and phylogenetic research with Paradiplozoon yunnanensis n. sp., including their host species, locality, GenBank accession number and sequence length.

\begin{tabular}{|c|c|c|c|c|}
\hline Parasite species & Host species & Locality & $\begin{array}{c}\text { GenBank accession } \\
\text { number }\end{array}$ & $\begin{array}{l}\text { Length } \\
\text { (bp) }\end{array}$ \\
\hline 1. Eudiplozoon nipponicum (Goto, 1891) & Cyprinus carpio (Linnaeus, 1758) & Morava River, Czech Republic & AJ300710 & 755 \\
\hline 2. E. nipponicum (Goto, 1891) & Cyprinus carpio (Linnaeus, 1758) & France & AF369758 & 977 \\
\hline 3. E. nipponicum (Goto, 1891) & Cyprinus carpio (Linnaeus, 1758) & Irtysh River, China & KP340975 & 772 \\
\hline 4. E. nipponicum (Goto, 1891) & Cyprinus carpio (Linnaeus, 1758) & Tangxun Lake, China & DQ098895 & 805 \\
\hline 5. E. nipponicum (Goto, 1891) & Cyprinus carpio (Linnaeus, 1758) & Danjiangkou Reservoir, China & DQ098897 & 804 \\
\hline 6. Paradiplozoon vaalense (Dos Santos, 2013) & Labeo umbratus (Smith, 1841) & Vaal River, South Africa & HG423142 & 700 \\
\hline 7. P. krugerense (Dos Santos, 2016) & $\begin{array}{l}\text { Labeo rosae (Steindachner, 1894) \& } \\
\text { Labeo congoro (Peters, 1852) }\end{array}$ & Kruger National Park, South Africa & LT574865 & 757 \\
\hline 8. P. ichthyoxanthon (Avenant-Oldewage, 2013) & Labeobarbus aeneus (Burchell, 1822) & Vaal River, South Africa & HF566124 & 733 \\
\hline 9. P. skrjabini (Achmerov, 1974; Khotenovsky,1985) & Rhynchocypris lagowskii (Dybowski, 1869) & Narva River, Russia & LC050529 & 683 \\
\hline 10. P. nagibinae (Gläser, 1965) & Abramis ballerus (Linnaeus, 1758) & Kyjovka River, Czech Republic & AJ563371 & 761 \\
\hline 11. P. pavlovskii (Bychowsky \& Nagibina, 1959) & Abramis aspius (Linnaeus, 1758) & Morava River, Czech Republic & AJ300714 & 770 \\
\hline 12. P. sapae (Reichenbach-Klinke, 1961) & Abramis sapa (Pallas, 1814) & Morava River, Czech Republic & AJ300713 & 769 \\
\hline 13. P. bliccae (Reichenbach-Klinke, 1961) & Bliccae bjoerkna (Linnaeus, 1758) & Morava River, Czech Republic & AJ300712 & 736 \\
\hline 14. P. megan (Bychowsky \& Nagibina, 1959) & Leuciscus cephalus (Linnaeus, 1758) & Morava River, Czech Republic & AJ300711 & 774 \\
\hline 15. P. bingolensis (Civáňová et al., 2013) & Garra rufa (Heckel, 1843) & Murat River, Turkey & HE653910 & 725 \\
\hline 16. P. gracile (Reichenbach Klinke, 1961) & Gobio acutipinnatus (Men'schikov, 1939) & Irtysh River (Chinese section), China & KP340973 & 764 \\
\hline 17. P. homoion (Bychowsky \& Nagibina, 1959) & Rutilus rutilus lacustris (Pallas, 1814) & Irtysh River (Chinese section), China & KP340972 & 764 \\
\hline 18. P. diplophyllorchidis (Jiang et al., 1985) & Zacco platypus (Temminck \& Schlegel, 1846) & Danjiangkou Reservoir, China & DQ098891 & 821 \\
\hline 19. P. hemiculteri (Ling, 1973) & Hemiculter leucisculus (Basilewsky, 1855) & Honghu, China & DQ098892 & 822 \\
\hline 20. P. opsariichthydis (Jiang et al., 1984) & $\begin{array}{l}\text { Opsariichthys uncirostris (Temminck \& Schlegel, } \\
\text { 1846) }\end{array}$ & Danjiangkou Reservoir, China & DQ098890 & 822 \\
\hline 21. P. parabramisi (Ling, 1973) & Parabramis pekinensis (Basilewsky, 1855) & Tangxun Lake, China & DQ098889 & 821 \\
\hline 22. P. jiangxiensis (Jiang et al., 1985) & Cultrichthys erythropterus (Basilewsky, 1855) & Tangxun Lake China & DQ098885 & 822 \\
\hline 23. P. parapeleci (Jiang et al., 1984) & Parapelecus argenteus (Günther, 1889) & Danjiangkou Reservoir, China & DQ098882 & 822 \\
\hline 24. Paradiplozoon yunnanensis n. sp. & Sikukia gudgeri (Smith, 1931) & Lancang River, China & MF775370* & 799 \\
\hline
\end{tabular}

* New sequence obtained in the present study. 

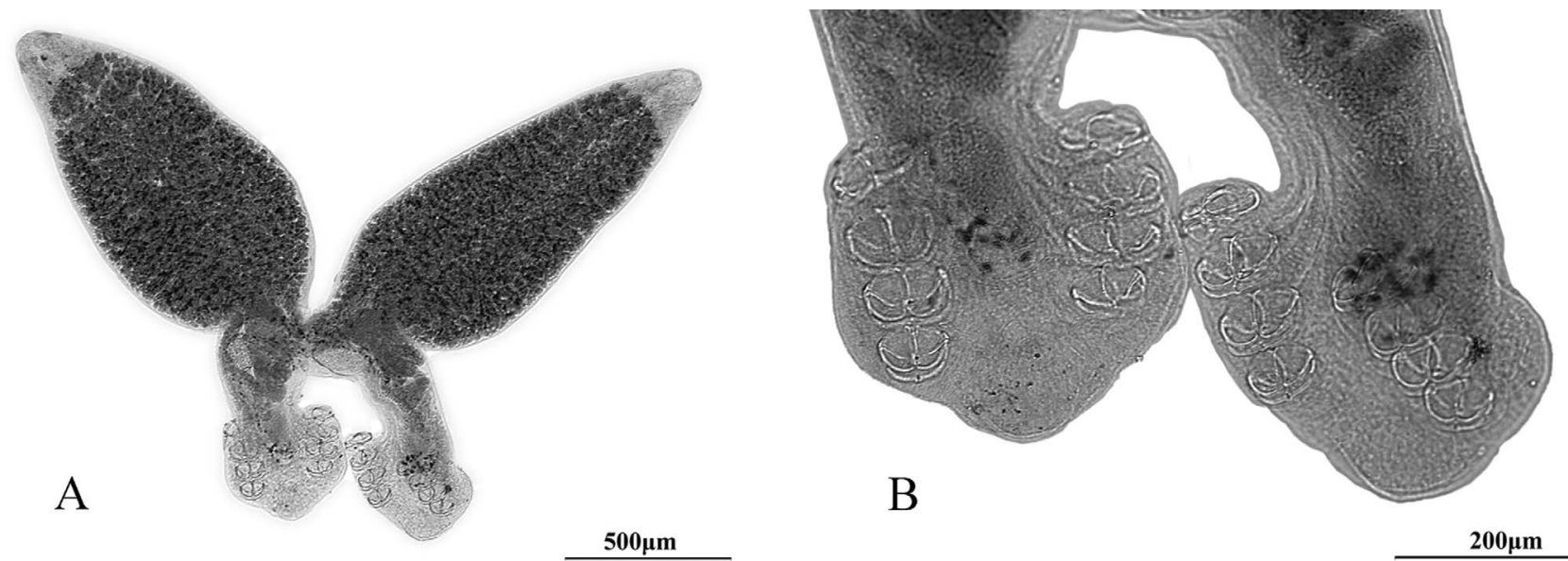

Figure 1. (A) Adult pairs of the parasites fuse in a permanent " $X$ " shape during copulation. (B) Haptor disc-like without a pronounced inflated terminal end.

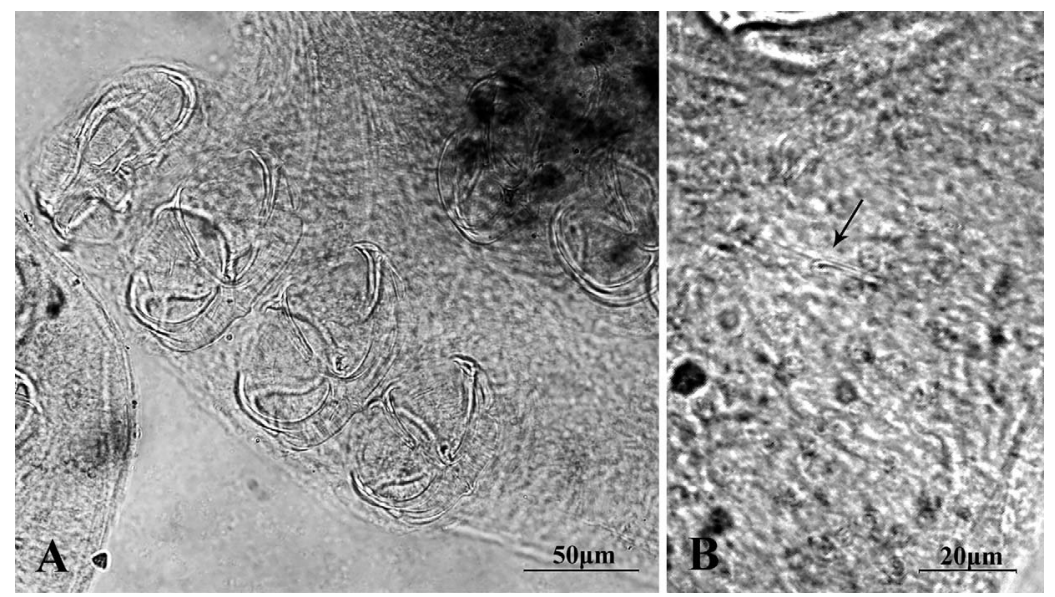

Figure 2. (A) Opisthaptors with four pairs of clamps and (B) a pair of central hooks.

Site of infection: Gills.

Type locality: Jinghong Basin of the Lancang-Mekong River, Yunnan Province, southwest China (22.007777 N, 100.795277 E).

Prevalence of infection: $20 \%$ (in total, 12 out of 59 fish).

Intensity of infection: 1-4 with a mean of two parasites per infected fish.

Etymology: The scientific name refers to the name of the province, Yunnan, where the new species was discovered.

Type material: Holotype (X22013.11.13) and four paratypes (M72012.10.29, X32013.11.02, A22013.11.12 and A32013.11.12) deposited at the Section of Zoology, School of Life Sciences of Yunnan Normal University, Kunming, Yunnan Province, China.

\section{Morphological description}

Adult pairs of the parasites fuse in a permanent " $X$ " shape during copulation (Fig. 1A) with a total body length of $1593 \mu \mathrm{m}(n=10,1148-2344 \mu \mathrm{m})$. Anterior tegument relatively smooth with extremely slight annular transverse folds or plicae. Anterior region approximately $1025 \mu \mathrm{m}$ long $(n=10,676-1478 \mu \mathrm{m})$ and $445 \mu \mathrm{m}$ wide $(n=10,211-$
$626 \mu \mathrm{m})$. Sub-terminal mouth present on the antero-ventral surface, opens into buccal cavity containing two buccal round suckers approximately $46 \mu \mathrm{m}$ long $(n=6,23-65 \mu \mathrm{m})$ and $35 \mu \mathrm{m}$ wide $(n=6,26-44 \mu \mathrm{m})$. Oval, muscular pharynx $45 \mu \mathrm{m}$ long $(n=10,30-56 \mu \mathrm{m}), 38 \mu \mathrm{m}$ wide $(n=10,21-$ $52 \mu \mathrm{m})$. Pharynx opens into highly branched intestine in the forebody with prominent lateral caeca and distributed vitellaria. Intestine extends from fusion area to hindbody, intestinal caeca pass through reproductive organs and end near attachment apparatus. Haptor disc-like without a pronounced inflated terminal end (Fig. 1B).

Main parts of male and female reproductive organs located in hindbody. Ovary long and strip shaped. Testis, solid and oval-shaped, posterior to the ovary. Eggs oval-shaped, $151 \mu \mathrm{m}$ long $(n=4,142-160 \mu \mathrm{m}), 75 \mu \mathrm{m}$ wide $(n=4,74$ $87 \mu \mathrm{m})$, with long curly filament. Follicular vitellaria, welldeveloped, in fusion region and to the end of hindbody, where the vitelline reservoir forms.

Opisthaptors with four pairs of clamps (Fig. 2A) and a pair of central hooks (Fig. 2B). First clamp $39 \mu \mathrm{m}$ long $(n=9,18$ $59 \mu \mathrm{m}), 53 \mu \mathrm{m}$ wide $(n=9,23-78 \mu \mathrm{m})$. Second clamp $44 \mu \mathrm{m}$ long $(n=9,20-65 \mu \mathrm{m}), 61 \mu \mathrm{m}$ wide $(n=9,27-86 \mu \mathrm{m})$. Third clamp $43 \mu \mathrm{m}$ long $(n=9,17-61 \mu \mathrm{m}), 62 \mu \mathrm{m}$ wide 
A

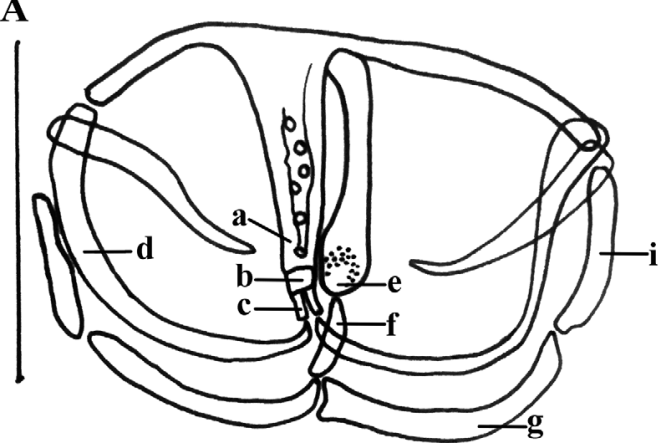

Figure 3. (A) Sclerites of posterior jaw divided into medial parts and lateral parts. (B) Point of the central hooks curls inward.

$(n=9,29-89 \mu \mathrm{m})$. Fourth clamp $46 \mu \mathrm{m}$ long $(n=9,20$ $59 \mu \mathrm{m}), 62 \mu \mathrm{m}$ wide $(n=9,27-87 \mu \mathrm{m})$. The first clamp is the smallest, other clamps are similar.

Clamps formed by slender sclerites. Sclerites of the anterior jaw with slight serrated edge. A longitudinal column of round sclerites in the middle part of the median plate. Anterior end of median plate thickened in marginal area; a narrow rectangular trapeze spur connects to the anterior jaw through two separate anterior joining sclerites. Posterior end of median plate sclerite invaginated. Posterior joining sclerite smooth strip-shaped and longer than the anterior joining sclerites. Sclerites of posterior jaw divided into medial parts and lateral parts (Fig. 3A).

Central hooks located between terminal protrusion of the haptor and first pair of clamps. Length of central hook sickle $12 \mu \mathrm{m}(n=2)$, handle length $21.5 \mu \mathrm{m}(n=2)$. Point of the central hooks curls inward (Figs. 2B, 3B).

\section{Molecular analysis}

The obtained final sequence (consensus of three individuals, 100\% identity) was 799 bp long (GenBank MF775370). The sequence was analysed with BLAST (base composition). The alignment of ITS2 sequences of 24 taxa was $720 \mathrm{bp}$ in length (including gaps), including 286 conserved sites, 429 variable sites and 349 parsimony informative sites.

Compared with 18 previously submitted sequences of Paradiplozoon and five sequences of Eudiplozoon (Table 1) to estimate homogeneity by similarity and genetic distance, the obtained rDNA sequence showed similarity to known species, e.g., identity of $89 \%$ with $P$. hemiculteri (DQ098892), P. diplophyllorchidis (DQ098891), P. opsariichthydis (DQ098890), and P. parabramisi (DQ098883), and $82 \%$ with $P$. ichthyoxanthon (HF566124). The most closely related species to $P$. yunnanensis $\mathrm{n}$. sp. were six species recorded from China (P. diplophyllorchidis, P. opsariichthydis, P. parabramisi, P. jiangxiensis (DQ098885), P. hemiculteri (DQ098892) and P. parapeleci) and two other species (P. bingolensis (HE653910) from Turkey and $P$. krugerense (LT574865) from South Africa), with estimated genetic distances (Kimura 2-parameter) of 0.13 and 0.36 , respectively (Table 2).
According to the rooted condensed tree (with 50\% cut-off value) based on the NJ/ML/MP analysis method with E. nipponicum as the outgroup (Fig. 4), the new species clustered between two phylogenetic clades: one clade including P. bingolensis and $P$. krugerense and another clade with six Chinese species of Paradiplozoon species (including $P$. diplophyllorchidis, P. opsariichthydis, P. parabramisi, P. jiangxiensis, $P$. hemiculteri and P. parapeleci). The molecular phylogenetic results corroborated morphological taxonomic results and supported $P$. yunnanensis $\mathrm{n}$. sp. as a new taxon.

\section{Discussion}

The Diplozoinae are divided into five genera using the dichotomic keys developed by Khotenovsky [15]. These genera are differentiated based on the presence-absence of dilatation in the middle part of the haptor, the shape and length of lateral branches departing from the intestinal caecum in the posterior end of the body, presence and size of plicae, location of uterine pore, and presence of glandular structures before the suckers [32]. Paradiplozoon is the most diverse genus of Diplozoinae and is distinguished from other genera by the absence of a pronounced dilatation in the posterior region of the prehaptor $[12,26]$. The posterior part of the specimens in the present study is without tegumental ridges or folds and was not cup-shaped or saucer-shaped. The specimens herein are ascribed to this genus based on the absence of these characters, which is typical of Paradiplozoon.

Morphological features (e.g. size of body, size of clamps) vary widely within diplozoid species, depending on size of the host fish and developmental stage of the parasite, making determination to species level difficult $[13,21]$. The sclerotized structures such as central hooks and clamp sclerites are considered the structures of most taxonomic relevance for determination of species within the genus Paradiplozoon, including the length of the central hook sickle and the shapes of the anterior end of median plate and anterior joining sclerites of the clamps $[11,15,20-22,25,27]$. However, the size of the clamps depends on the total length of host fish [8]. The shapes of the trapeze spur and the anterior joining sclerites were used for identifying species [22]. In the present study, the combination of morphological features of clamp and the central hook demonstrates the specimens described herein differ from all other Paradiplozoon species.

Monogeneans are monoxenous ectoparasites characterized by a relatively high degree of host specificity, and host specificity has previously been used as a basis for species discrimination. However, Paradiplozoon homoion displays low host specificity and infects more than 15 cyprinid host species [22]. Paradiplozoon yunnanensis n. sp. is the first and only diplozoid species reported from $S$. gudgeri but this cannot be used as the single argument to demonstrate the validity of the species. Molecular methods based on genetic features of nucleotide sequencing of ITS2 have been suggested as powerful tools for distinguishing species of Paradiplozoon [8, 19-22]. Compared with 18 previously submitted sequences of Paradiplozoon, the ITS2 sequence of P. yunnanensis n. sp. showed $82 \%-89 \%$ similarity to already known species. 
Table 2. Pairwise distance (kimura 2-parameter) matrix for the complete ITS2 sequences across all sequences from diplozoid species.

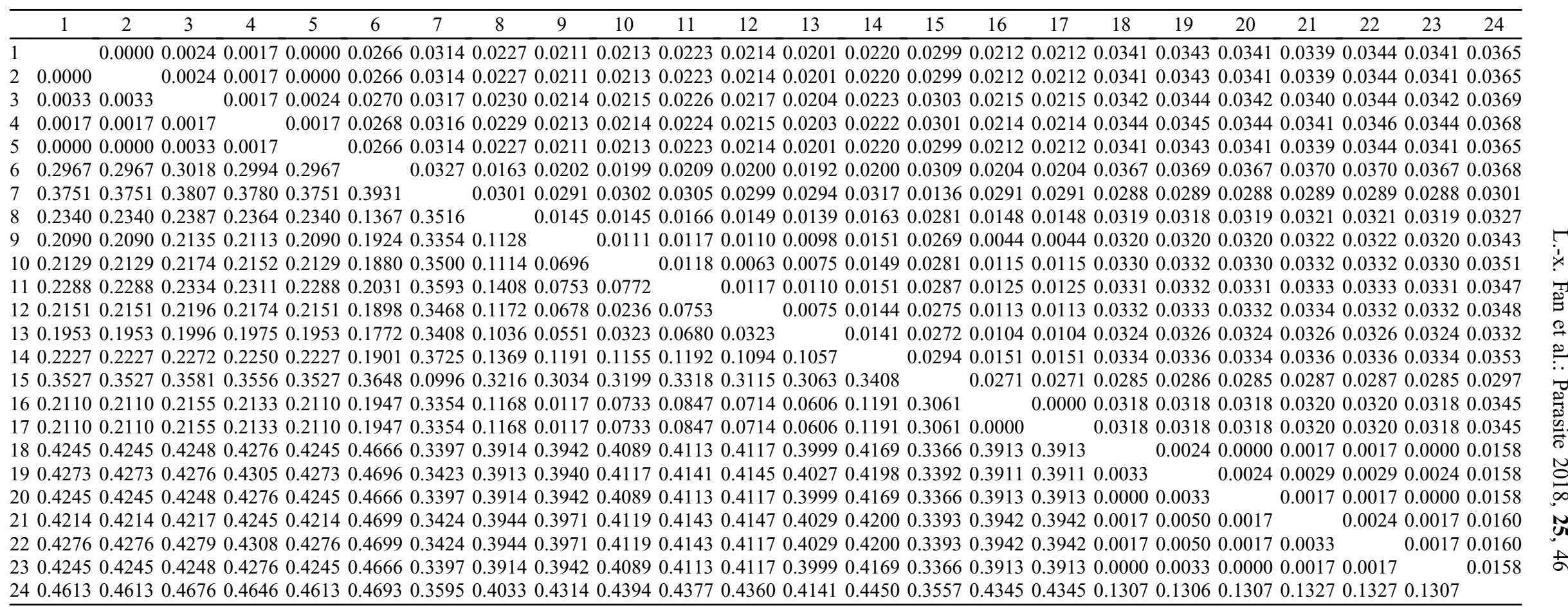

Pairwise distances (kimura 2-parameter) between species are shown under the diagonal. Standard error estimates are shown above the diagonal. Appellations of 24 taxa are stated below.1 Eudiplozoon nipponicum (AJ300710), 2 E. nipponicum (AF369758), 3 E. nipponicum (KP340975), 4 E. nipponicum (DQ098895), 5 E. nipponicum (DQ098895), 6 Paradiplozoon vaalense (HG423142), 7 P. krugerense (LT574865), 8 P. ichthyoxanthon (HF566124), 9 P. skrjabini (LC050529), 10 P. nagibinae (AJ563371), 11 P. pavlovskii (AJ300714), 12 P. sapae (AJ300713), 13 P. bliccae (AJ300712), 14 P. megan (AJ300711), 15 P. bingolensis (HE653910), 16 P. gracile (KP340973), 17 P. homoion (KP340972), 18 P. diplophyllorchidis (DQ098891), 19 P. hemiculteri (DQ098892), 20 P. opsariichthydis (DQ098890), 21 P. parabramisi (DQ098889), 22 P. jiangxiensis (DQ098885), 23 P. parapeleci (DQ098882), 24 Paradiplozoon yunnanensis n. sp. (MF775370). 


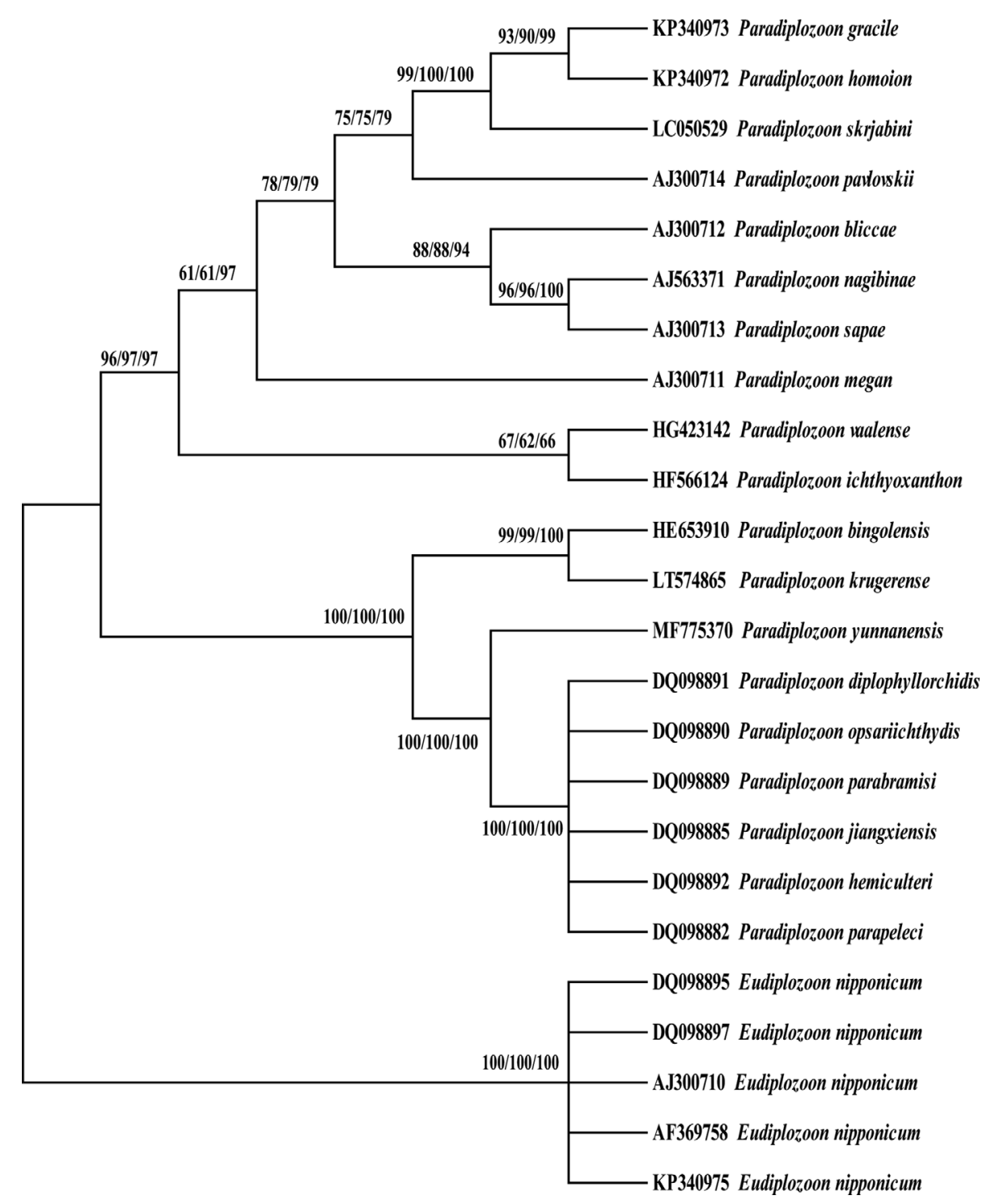

Figure 4. The rooted condensed tree (with $50 \%$ cut-off value) based on the NJ/ML/MP analysis method.

Paradiplozoon yunnanensis n. sp. was most closely related to six Chinese species, $P$. bingolensis and $P$. krugerense, with estimated genetic distances of 0.13 and 0.36 respectively, and was placed in the Paradiplozoon clade in the phylogenetic tree. The results combined with morphological characteristics support P. yunnanensis $\mathrm{n}$. sp. as a valid species.

Our research provides some information about the phylogenetic status and relationships of 18 species of Paradiplozoon by analysing and estimating homogeneity and genetic distance. There are nine species of Chinese Paradiplozoon in the reconstructed phylogenetic tree. The Chinese diplozoids P. gracile (KP340973) and P. homoion (KP340972) clustered in a clade with P. skrjabini from Russia (LC050529) firstly, and then with other European diplozoids, including P. pavlovskii (AJ300714), P. bliccae (AJ300712), P. nagibinae (AJ563371), P. sapae (AJ300713) and P. megan (AJ300711). The NJ topology may be caused by $P$. gracile (KP340973) and $P$. homoion (KP340972) being collected from the Ergis
River, Chinese section of the Irtysh River. The Ergis River is the only international river of the Arctic Ocean in China. It originates in the mountains of Altai, northern Xinjiang, China and flows through the Sino Mongolian border [29, 30]. Our results indicate that Chinese diplozoids $P$ gracile (KP340973) and P. homoion (KP340972) are very closely related to European diplozoids; this could occur through possible host migration under certain conditions in the Arctic Ocean, which would cause the homogeneity of fish and fish monogeneans.

Paradiplozoon yunnanensis $\mathrm{n}$. $\mathrm{sp}$. was confirmed as a new taxon that clustered closely to the clade composed of the other six species of Chinese Paradiplozoon with 100\% bootstrap support (similarity 82-89\%). In addition, our analysis presented significantly non-different genetic distances between the following Chinese species: P. opsariichthydis, P. parabramisi, $P$. jiangxiensis, $P$. hemiculteri, and $P$. parapeleci. According to Gao et al., the ITS2 sequences of the latter species 
reached 99\% similarity, with interspecific similarity (>99\%) between these congeneric species [10]. Only 4 positions were parsimony informative and 13 positions were variable, with 822 conserved positions. Because the BLAST comparison results were the same, Civáňová et al. suggested that the identification of the mentioned Chinese species as different ones was incorrect and strongly suggested their further reclassification [8]. According to Jirsová et al., related sequences available in GenBank are probably misnamed as P. hemiculteri [13]. Furthermore, morphological characteristics may be variable within species and congeneric species. Therefore, we agree that morphological differences and host species are not the most suitable taxonomical features for identifying congeners. On the other hand, the geographical distribution of hosts plays an important role in the occurrence and host-specificity of diplozoids. According to Reichenbach-Klinke, Diplozoon homoion Bychowsky and Nagibina is predominant in Central Europe and is probably divided into subspecies [24]. Taxonomic studies of Chinese Paradiplozoon diplozoids are necessary. It is worthy of further study to supplement molecular information of Chinese recorded Paradiplozoon to provide suitable indicators for precluding morphological resemblance among these species.

The Lancang-Mekong River is an international river in Asia. It flows through China, Myanmar, Laos, Thailand, Cambodia and Vietnam, and is called Lancang River in southwest China, Yunnan Province. The geographical position of the river is responsible for its unique biological diversity [14]. There are 13 orders, 42 families, 198 genera and 620 valid fish species recorded in Yunnan Province. Of these fishes, 586 species are native species, 34 are alien species, and 254 are endemic to Yunnan, with more than 300 species of the family Cyprinidae and 152 species occurring within China only in Yunnan Province. The freshwater fish fauna in the Lancang River (upper Mekong) has a distinctly rich biodiversity, with 12 subfamilies, 105 genera and 183 species [6]. Although diplozoids are generally considered parasites of cyprinid species, only 36 species have been recorded in China; some species require further study. Cyprinids are currently the only recorded fish family hosting diplozoids in south-eastern Asia [18, 21]. Description of new taxa and molecular phylogeny will contribute to a clearer understanding of the mechanism of historical biogeography and coevolution of Monogenea-fish associations in south-eastern Asia.

Acknowledgements. This research was financed by the National Natural Science Foundation of China (No. 30660022, No. 30960049, No. 31260507 and No. 31560589) and Yunnan Provincial Sciences and Technology Department (No. 2005C0019Q and No. 2009CD049). We greatly appreciate Professor Xuejuan Ding (South China Normal University, Guangzhou, China), and Professor Tingbao Yang (Sun Yat-sen University, Guangzhou, China) for assistance with classification. We also wish to thank Jianjun Wang (Station of Environmental Monitor of Xishuangbanna, Jinghong, China) for collecting fish hosts and Yunzhen Li and Yonghong Zhang (School of Life Sciences of Yunnan Normal University, Kunming, China) for analysing molecular phylogenetic data. We are grateful to Professor Claude Combes (Parasitologie Fonctionnelle et Évolutive, Université Perpignan, France) for providing references. We thank Dr Iva Přikrylová (Masaryk University, Brno, Czech Republic), Prof Louis Du
Preez (North West University, Potchefstroom, South Africa), and the Editor-in-Chief, Prof Jean-Lou Justine, for their help with this manuscript.

\section{Conflict of interest}

All authors have no conflict of interest. We acted in accordance with all applicable institutional and national laws and guidelines during this research.

\section{References}

1. Ahmad F, Fazili KM, Sofi TA, Sheikh BA, Waza AA, Rashid R, Gani TT. 2015. Morphological and molecular characterization of Diplozoon kashmirensis; D. aegyptensis and D. guptai collected from fishes of Kashmir valley-India. Fisheries and Aquaculture Journal, 6, 147.

2. Al-Nasiri FS, Balbuena JA. 2013. Paradiplozoon iraqensis n. sp. (Monogenea: Diplozoinae) from Cyprinion macrostomum (Cyprinidae) in the Tigris River, Iraq. Acta Parasitologica, 61, 291-298.

3. Avenant-Oldewage A, Le RL, Mashego SN, van Vuuren BJ. 2014. Paradiplozoon ichthyoxanthon n. sp. (Monogenea: Diplozoidae) from Labeobarbus aeneus (Cyprinidae) in the Vaal River, South Africa. Journal of Helminthology, 88, 166-172.

4. Bai JP, Wang JJ, Li J, Xu WJ, Fan LX. 2014. A new species of genus Paradiplozoon parasitic in Sikukia flavicaudata from the Lancang River, Xishuangbanna, Yunnan. Sichuan Journal of Zoology, 33, 541-544.

5. Bombarová M, Špakulová M, Koubková B. 2014. New data on the karyotype and chromosomal rDNA location in Paradiplozoon megan (Monogenea, Diplozoidae), gill parasite of chubs. Parasitology Research, 113, 4111-4116.

6. Chen XY. 2013. Checklist of fishes of Yunnan. Zoological Research, 34, 281-343.

7. Chu XL, Chen YR. 1990. The fishes of Yunnan, China. Science Press: Beijing, China.

8. Civáňová K, Koyun M, Koubková B. 2013. The molecular and morphometrical description of a new diplozoid species from the gills of the Garra rufa (Heckel, 1843) (Cyprinidae) from Turkey including a commentary on taxonomic division of Diplozoidae. Parasitology Research, 112, 3053-3062.

9. Cunningham CO. 1997. Species variation within the internal transcribed spacer (ITS) region of Gyrodactylus (Monogenea: Gyrodactylidae) ribosomal RNA genes. Journal of Parasitology, 83, 215-219.

10. Gao Q, Chen MX, Yao WJ, Gao Y, Song Y, Wang GT, Wang MX, Nie P. 2007. Phylogeny of diplozoids in five genera of the subfamily Diplozoinae Palombi, 1949 as inferred from ITS-2 rDNA sequences. Parasitology, 134, 695-703.

11. Gläser HJ, Gläser B. 1964. Zur taxonomie der gattung Diplozoon Nordmann, 1832. Zeitschrift für Parasitenkunde, 25, 164-192.

12. Gussev AV, Kulemina IV. 1971. Analysis of variability of characters, behaviour and development cycle of monogeneans from the age of host. Parazitologiya, 5, 320-329 (In Russian).

13. Jirsová $\mathrm{D}$, Ding $\mathrm{X}$, Civánová $\mathrm{K}$, Jirounková E, Ilgová J, Koubková B, Kasny M, Gelnar M. 2018. Redescription of Paradiplozoon hemiculteri (Monogenea, Diplozoidae) from the type host Hemiculter leucisculus, with neotype designation. Parasite, 25, 4 
14. Kang B, He DM. 2007. Research progress of biodiversity of fish species in the Lancangjiang River. Resources Sciences, 29, 195-200.

15. Khotenovsky IA. 1985. Suborder Discocotylinea Bychowsky, 1957, in Key to Parasites of Freshwater Fish. Fauna of the USSR. Bauer ON, Editor. Izdatel'stvo "Nauka": Leningrad. p. 354-387 (In Russian).

16. Konstanzová V, Koubková $B$, Kašný M, Ilgová J, Dzika E, Gelnar M. 2015. Ultrastructure of the digestive tract of Paradiplozoon homoion (Monogenea). Parasitology Research, 114, 1485-1494.

17. Konstanzová V, Koubková B, Kašný M, Ilgová J, Dzika E, Gelnar M. 2017. An ultrastructural study of the surface and attachment structures of Paradiplozoon homoion (Bychowsky \& Nagibina, 1959) (Monogenea: Diplozoidae). Parasites \& Vectors, 10, 261.

18. Lim LH. 1998. Diversity of monogeneans in Southeast Asia. International Journal for Parasitology, 28, 1495-1515.

19. Matějusová I, Gelnar M, Mcbeath AJ, Collins CM, Cunningham CO. 2001. Molecular markers for gyrodactylids (Gyrodactylidae: Monogenea) from five fish families (Teleostei). International Journal for Parasitology, 31, 738-745.

20. Matějusová I, Koubkova B, D'Amelio S, Cunningham CO. 2001. Genetic characterization of six species of diplozoids (Monogenea; Diplozoidae). Parasitology, 123, 465-474.

21. Matějusová I, Koubková B, Gelnar M, Cunningham CO. 2002. Paradiplozoon homoion Bychowsky \& Nagibina, 1959 versus P. gracile Reichenbach-Klinke, 1961 (Monogenea): two species or phenotypic plasticity? Systematic Parasitology, 53, 39-47.

22. Matějusová I, Koubková B, Cunningham CO. 2004. Identification of European diplozoids (Monogenea, Diplozoinae) by restriction digestion of ribosomal RNA internal transcribed spacer. Journal for Parasitology, 90, 817-822.

23. Olson PD, Tkach VV. 2005. Advances and trends in the molecular systematics of the parasitic Platyhelminthes. Advances in Parasitology, 60, 165-243.

24. Reichenbach-Klinke HH. 1980. Contributions to the taxonomy of the Genus Diplozoon von Nordmann, 1832. In: Fish diseases.
Proceedings in Life Sciences. Ahne W., Editor. Springer: Berlin, Heidelberg.

25. Dos Santos QM, van Vuuren BJ, Avenant-Oldewage A. 2015. Paradiplozoon vaalense n. sp. (Monogenea: Diplozoidae) from the gills of moggel, Labeo umbratus (Smith, 1841), in the Vaal River System, South Africa. Journal of Helminthology, 89, $58-67$.

26. Dos Santos QM, Avenant-Oldewage A. 2015. Soft tissue digestion of Paradiplozoon vaalense for SEM of sclerites and simultaneous molecular analysis. Journal of Parasitology, 101, 94-97.

27. Dos Santos QM, Avenant-Oldewage A. 2016. The description of a new diplozoid species, Paradiplozoon krugerense, n. sp. from Labeo rosae, Steindachner, 1894 and Labeo congoro, Peters, 1852 in the Kruger National Park, South Africa with notes on the effect of water quality on its infection variable. Hydrobiologia, 777, 225-241.

28. Sicard M, Desmarais E, Vigneux F, Shimazu T, Lambert A. 2003. Molecular phylogeny of the Diplozoidae (Monogenea, Polyopisthocotylea) parasitising 12 species of Cyprinidae (Teleostei): new data about speciation. In: Taxonomie, Ecologie et Évolution des Métazoaires parasites. Taxonomy, Ecology and Evolution of Metazoan Parasites. Livre hommage à Louis Euzet. Combes C, Jourdane J. Presses Universitaire de Perpignan: Perpignan, p. 199-211

29. Wang X, Jiao L, Jia SA, Wang N, Hao CL, Zhu M, Yue C. 2014. A new record of Diplozoidae in China. Arid Zone Research, 31, 1121-1124.

30. Wang X, Jiao L, Yao WJ, Hao CL, Yue C. 2015. The first record of a newly reported Chinese Diplozoidae of Monogenea of fishes in the Ergis River. Acta Hydrobiologica Sinica, 39, 794-797.

31. Wong WL, Tan WB, Lim LH. 2006. Sodium dodecyl sulphate as a rapid clearing agent for studying the hard parts of monogeneans and nematodes. Journal of Helminthology, 80, 87-90.

32. Wu BH, Lang S, Wang WJ. 2000. Fauna Sinica: Platyhelminthes: Monogenea. Science Press: Beijing, China.

Cite this article as: Fan L, Meng F, Bai J, Xu W \& Wang X. 2018. Paradiplozoon yunnanensis n. sp. (Monogenea, Diplozoidae) from Sikukia gudgeri (Cyprinidae, Barbinae) in southwest China. Parasite 25, 46.

Reviews, articles and short notes may be submitted. Fields include, but are not limited to: general, medical and veterinary parasitology; morphology, including ultrastructure; parasite systematics, including entomology, acarology, helminthology and protistology, and molecular analyses; molecular biology and biochemistry; immunology of parasitic diseases; host-parasite relationships; ecology and life history of parasites; epidemiology; therapeutics; new diagnostic tools.

All papers in Parasite are published in English. Manuscripts should have a broad interest and must not have been published or submitted elsewhere. No limit is imposed on the length of manuscripts.

Parasite (open-access) continues Parasite (print and online editions, 1994-2012) and Annales de Parasitologie Humaine et Comparée (1923-1993) and is the official journal of the Société Française de Parasitologie. 